\title{
O PROCESSO DE ELABORAÇÃO DAS PROPOSTAS CURRICULARES PARA A EDUCAÇÃO BÁSICA
}

\author{
F.G.O TAVARES \\ Universidade de São Paulo \\ fernando.gomes.tavares@usp.br*
}

Artigo submetido em 14/12/2017 e aceito em 05/11/2019

DOI: $10.15628 /$ holos.2019.6678

\section{RESUMO}

Este artigo apresenta uma análise comparativa documental do processo de elaboração dos Guias Curriculares, da Proposta da Coordenadoria de Estudos e Normas Pedagógicas (CENP), dos Parâmetros Curriculares Nacionais, das Diretrizes Curriculares do Paraná e do Currículo de São Paulo. Os resultados

consistem na descrição cronológica do contexto sociopolítico e das concepções didático-pedagógicas que originaram esses documentos. Conclui-se que a criação dessas propostas curriculares revelou, como principal característica, a ausência de uma discussão participativa com os professores da educação básica.

PALAVRAS-CHAVE: currículo, educação básica, propostas curriculares, teoria curricular.

\section{THE PROCESS OF CREATING CURRICULAR PROPOSALS FOR BASIC EDUCATION}

\begin{abstract}
This article presents a comparative documentary analysis of the process the Guias Curriculares, the Proposta da CENP, the Parâmetros Curriculares Nacionais, the Diretrizes Curriculares do Paraná and Currículo de São Paulo. The results consist of the chronological description of the sociopolitical context and the didactic-pedagogical
\end{abstract}

conceptions that gave rise to these documents. The results showed that the creation of these curricular proposals revealed, as main characteristic, the absence of a participative discussion with the teachers of the basic education.

KEYWORDS: curriculum, basic education, curricular proposals, curricular theory. 


\section{INTRODUÇÃO}

Não existe uma resposta simples para a pergunta "o que é currículo?". Os estudos curriculares, desde o início do século passado, têm definido currículo de maneiras muito diversas e várias dessas definições passam pela acepção corrente que é estabelecida pelo cotidiano escolar. Partindo dos documentos oficiais, implantados pelas diversas políticas educacionais, àquilo que acontece em sala de aula, o currículo é comumente relacionado ao conjunto de ementas, à grade disciplinar, aos planos de ensino, aos planos de aula e às experiências vividas pelos estudantes. Existe, certamente, uma característica comum a tudo isso que tem sido chamado de currículo: a ideia de organização de experiências de aprendizagem realizada por professores para conduzir um processo educativo (Lopes \& Macedo, 2011). No entanto, sob tal definição, se esconde uma série de outras questões que vêm sendo objeto de disputa dentro das teorias do currículo.

Existiram inúmeras correntes de pensamento no campo das investigações curriculares, mas as principais teorias do currículo, e que serão tratadas aqui, em que se baseiam as ideias que permeiam a organização curricular são: as teorias tradicionais, as teorias críticas e as teorias póscríticas. As propostas curriculares resultantes dessas teorias exercem um papel relevante dentro da política educacional, uma vez que servem como base para a confecção de materiais didáticos e orientação das políticas de formação docente. Dessa forma, o currículo corresponde a um objeto de análise de grande interesse para a compreensão do ambiente pedagógico, levando em conta o problema da imposição e da apropriação de certos padrões educacionais.

Este artigo, apresenta uma análise comparativa documental do processo de elaboração de cinco propostas curriculares: os Guias Curriculares, a Proposta da Coordenadoria de Estudos e Normas Pedagógicas (CENP), os Parâmetros Curriculares Nacionais, as Diretrizes Curriculares do Paraná e o Currículo de São Paulo. Essas propostas para a educação básica fazem parte da trajetória histórica da política curricular brasileira.

Para alcançar tal objetivo, a presente investigação orientou-se pelo entrelaçamento de dois procedimentos metodológicos, a pesquisa documental e a análise comparativa. Essa intersecção mostrou-se adequada para buscar as semelhanças e as diferenças, a partir da identificação de processos histórico-sociais, entre as propostas curriculares estudadas.

O trabalho divide-se basicamente em quatro partes. A primeira parte, evidencia o percurso das principais teorias curriculares: a teoria tradicional, a teoria crítica e a teoria pós-crítica. A segunda parte, realiza uma análise sobre a trajetória dos currículos oficiais situados entre o período da ditadura militar e o início da redemocratização do país. A terceira, procura revelar as inúmeras implicações oriundas da relação entre a elaboração dos Parâmetros Curriculares Nacionais (PCNs), do Currículo de São Paulo e das Diretrizes Curriculares do Paraná. A última parte do trabalho, conclui que os professores foram afastados do processo de produção curricular e sugere uma abertura democrática que possa configurar em uma maior participação dessa classe durante o planejamento propostas oficiais. 


\section{TEORIAS CURRICULARES}

Talvez pareça óbvia, hoje em dia, a afirmação de que o ensino necessita de um planejamento que envolve a seleção de determinados conteúdos e atividades para sua organização ao longo do processo de escolarização. Mas, nem sempre, essa ideia foi tão clara assim. Na segunda metade do século XIX, por exemplo, a acepção corrente era que as disciplinas possuíam conteúdos que lhes eram próprios e que suas peculiaridades estabeleciam os necessários fins para o desenvolvimento de certas faculdades mentais. O ensino tradicional (ou jesuítico) trabalhava com tais princípios. Defendia a tese de que somente algumas disciplinas escolares podiam facilitar o raciocínio lógico ou mesmo ampliar a capacidade de memorização. Somente na virada do século XIX, com o advento do processo industrial americano, e nos anos 1920, com o movimento escolanovista no Brasil, ganhou força o pensamento vigente de que é preciso determinar sobre aquilo que se vai ensinar nas escolas. Para a maioria dos autores, esse período é o ponto de partida dos estudos sobre o currículo ${ }^{1}$.

Dentro desse novo contexto, a sociedade exigiu uma revisão da maneira como estava sendo processada a formação dos seus cidadãos. Isso serviu de pauta para uma discussão governamental sobre um novo modelo de homem, que deveria possuir habilidades suficientes para se inserir nessa nova conjuntura social. Na tentativa de formar esse "novo homem", medidas foram propostas e atendidas por alguns profissionais do ramo educativo. Algumas regras e normas que direcionavam a formação desse novo perfil de cidadão foram discutidas, implementadas e veiculadas em diversos meios de comunicação. Foram através dessas discussões que nasceram as primeiras diretrizes curriculares, desmembrando-se nas denominadas teorias tradicionais do currículo.

As teorias tradicionais começaram a ser discutidas no ano de 1918, nos Estados Unidos, com o lançamento da obra "The Curriculum", escrita por Franklin Bobbitt. Este teórico teve um papel muito importante para o período, pois defendeu a incorporação de modelos de eficiência, baseados nas leis de administração científica, propostos pelo taylorismo². Para Bobbitt, a função do currículo era simplesmente preparar o jovem estudante para uma vida adulta economicamente ativa. Assim, segundo ele, as questões de cunho político, econômico e cultural procurariam se adaptar aos objetivos da educação de massa em conformidade com os interesses do sistema capitalista. Nesse momento, portanto, o currículo começava a ser visto como um importante instrumento de controle social.

Nesse sentido, os teóricos tradicionais defendiam um funcionamento das escolas à maneira das empresas. Apontavam um modelo escolar baseado no estabelecimento de objetivos, no sentido de desenvolver habilidades que, possivelmente, facilitariam a inserção dos estudantes no mercado de trabalho. Prescreviam, ainda, o estabelecimento de padrões industriais na escola, onde o

\footnotetext{
${ }^{1}$ Estudos históricos apontam que a primeira referência ao termo currículo data de 1633, aparecido nos registros da Universidade de Glasgow na Escócia para referir-se ao curso completo seguido pelos universitários. Apesar dessa menção ao termo não implicar um surgimento de um campo de estudos curriculares, vale ressaltar que ela já demonstra uma associação entre currículo e ordenamento da experiência educacional, aspecto presente em um dos mais consolidados sentidos da palavra currículo.

${ }^{2}$ Sistema de produção concebido pelo engenheiro estadunidense Frederick Taylor, com o qual se pretende atingir uma alta produtividade com o mínimo de tempo e de esforço.
}

HOLOS, Ano 35, v.2, e6678, 2019 
estudante pudesse ser moldado ao longo da sua formação e se transformar em um operário apto a cumprir suas obrigações específicas.

No Brasil essas ideias ganharam aceitação, na década de 1970, com a tradução do livro "Princípios Básicos de Currículo e Ensino" de Ralph Tyler. Este autor ampliou e reforçou as ideias de Bobbitt ao apontar que os objetivos e conteúdos do ensino deviam ser muito bem delimitados. Para ele, as tarefas ou os objetivos eram centrais e poderiam ser reunidas dentro das disciplinas que, nesta situação, já estariam presentes nos currículos. Tyler também incorporou e recomendou, em sua tese, as teorias comportamentalistas da psicologia como uma possível estratégia de controle para o tipo de formação escolar que se pretendia.

Os princípios de Tyler (1975) e de outros autores conhecidos do movimento tradicional como Kilpatrick (1918) e Dewey (1959) constituíram a base das reformas educacionais ocorridas em alguns estados brasileiros, levados a cabo por educadores escolanovistas. Fernando Azevedo e Anísio Teixeira, por exemplo, foram responsáveis pelas reformas curriculares ocorridas na Bahia e no Distrito Federal. É válido lembrar também que a proposta dos Centros Integrados de Educação Pública (CIEPs) foi baseada em elementos da teoria tradicional.

Os teóricos dessa vertente tradicional acreditavam na neutralidade do conhecimento e das relações, no processo de ensino e aprendizagem. O aspecto mais importante para eles, nesse momento, era a organização do ensino, enquanto a aprendizagem do sujeito estava em segundo plano dentro do processo educativo. Enxergavam o estudante como um mero reprodutor das informações advindas do currículo e todo o discurso que veiculavam estava respaldado no princípio da cientificidade. Sob essa ótica, é possível perceber o currículo tradicional como um produto organizado a partir de um enfoque técnico, previamente determinado e regido pela lógica burocrática.

Para rivalizar com as ideias da teoria tradicional do currículo, surgiram os autores da corrente crítica. Os teóricos desse movimento, que teve sua maior expressão nos anos 1970, criticavam as abordagens científicas curriculares pelo fato de conceberem a escola e o currículo como instrumentos de controle social. Embasados pelo pensamento marxista, os críticos defendiam a relação entre a base econômica e a superestrutura, partindo de perspectivas mecanicistas às concepções em que a dialética entre cultura e economia fazia-se mais visível. Desse modo, amparados pelo conceito de aparelhos ideológicos de Estado, desenvolvido por Louis Althusser (1998), investigavam a presença do sistema educativo na configuração dos sujeitos de cada classe social, no que diz respeito à execução dos papéis que lhes são designados pelo sistema capitalista.

Tal concepção de Althusser constituiu-se o cerne da teorização crítica do currículo. Ao explicar os mecanismos pelos quais o Estado colabora para a reprodução da estrutura de classes, o autor criou uma organização básica de conceitos com os quais a teoria crítica operaria. Althusser deu ênfase para o duplo caráter do papel da escola na manutenção da estrutura social: diretamente, ela atua como um elemento auxiliar do modo de produção gerando mão de obra e, indiretamente, difunde de forma diferenciada a ideologia que opera como mecanismo de atração das diferentes classes sociais. O currículo, por esse ângulo, pode ser considerado uma mistificação ideológica. 
Na trajetória das críticas ao papel reprodutivo do sistema de ensino, Michael Young, em 1971, lançou os fundamentos do movimento denominado Nova Sociologia da Educação (NSE). Para compreender como a diferenciação social era formada por meio do currículo, os autores da NSE apresentavam questões sobre a organização e a seleção do conhecimento escolar. Diferente das visões técnicas, essas questões procuravam entender os interesses implicados em tais processos, compreendendo que a escola legitima determinados conhecimentos e, mais especificamente, os grupos que os detêm. Assim, a elaboração do currículo começava a ser pensada como um processo social, ligado a determinações de uma sociedade dividida em classes. Inaugurava-se uma nova tradição nos estudos curriculares: a concepção de que o currículo forma o próprio conhecimento, e não apenas os estudantes, a partir do instante em que decide aquilo que é objeto da escolarização.

Foi, no entanto, apenas em 1979, com a publicação do livro "Ideologia e currículo", escrito por Michael Apple, que as análises críticas ganharam enorme popularidade na área e passaram a tratar especificamente do currículo. Apple defendia a correspondência entre dominação cultural e dominação econômica. Em interação, principalmente, com as questões apresentadas pela Nova Sociologia da Educação, o autor recuperou os conceitos de ideologia e hegemonia para refletir sobre a ação educativa na reprodução das desigualdades, excluindo perspectivas excessivamente deterministas. No Brasil, suas ideias alcançaram notoriedade na década de $1980 \mathrm{com}$ o processo de redemocratização. Após duas décadas de ditadura militar, marcadas pelo tecnicismo, têm-se as formulações de Paulo Freire $(1981,1985)$, ao mesmo tempo em que Libâneo (1985) lançava as bases da Pedagogia Crítico-Social dos conteúdos ou em que Saviani (1991), as bases da Pedagogia Histórico-Crítica.

A questão central, dentro dessa abordagem, não é mais "o que ou como ensinar", e sim por qual razão um pequeno número de aspectos da cultura social são ensinados como se representassem o todo social. A partir dessa indagação, Apple recriou o conceito de currículo oculto, definido nos anos 1960, pretendendo dar conta das questões de poder que permeavam o currículo. Ele afirma que por detrás do currículo formal existe um currículo oculto, em que se esconde as relações de poder originadas das supostas escolhas curriculares. Esse currículo oculto está presente em muitas manifestações curriculares. Na perspectiva tradicional, descrita anteriormente, tem-se um bom exemplo de currículo oculto registrado na própria maneira como os currículos são pensados. Ao optar por conjuntos ordenados de matérias para a definição do que ensinar e do como ensinar, tal perspectiva assume o fazer curricular como uma questão técnica, ocultando toda a dimensão ideológica existente nessa seleção. Essa perspectiva curricular também oculta outro fator social importante: a contradição.

Antes da passagem para a discussão da próxima corrente teórica, que também se ocupou em ocultar a contradição, faz-se necessário ressaltar que as teorias críticas e, principalmente, as ideias de Michael Apple, foram examinadas e revistas por inúmeros especialistas nos últimos anos. Embora Apple tenha defendido a escola como espaço de (re)produção, trata-se de um tipo de produção que apenas se podia fazer para atender às necessidades próprias do capital. Já com a entrada das teorias da resistência, que denunciavam o encarceramento da consciência da classe trabalhadora, o caráter contraditório próprio da reprodução capitalista acentuava-se. Essas teorias apresentaram um novo ponto de vista para que os sujeitos pudessem refletir na possibilidade de se 
tornarem agentes efetivos na mudança histórico-social, perspectiva impossibilitada pelas teorias críticas.

As teorias curriculares pós-críticas emergiram nos fins da década de 1970, com base nos princípios da fenomenologia, do pós-estruturalismo e dos ideais multiculturais. No Brasil, até os anos 1990, não existia praticamente nenhuma menção ao movimento pós-crítico nos estudos curriculares, algo que mudaria vigorosamente com as traduções realizadas por Tomaz Tadeu da Silva $^{3}$. Da mesma forma que as teorias críticas, o movimento pós-crítico também tecia duros pareceres aos teóricos tradicionais, mas optava por uma mudança de enfoque: das classes sociais para o ponto de vista do indivíduo. Desse modo, os pós-críticos estavam interessados em compreender para além da realidade social dos indivíduos e, assim, passaram a se preocupar também com os assuntos étnicos e culturais.

A teoria pós-crítica, sob o viés pós-estruturalista, pretendia adaptar o currículo ao contexto específico dos estudantes para que compreendessem, através dos costumes do outro, a relação entre diversidade e respeito. Assim, o currículo passou a representar a ideia de que não existe um conhecimento verdadeiro e único, sendo esse uma questão de perspectiva histórica, ou seja, que se modifica nos diferentes tempos e espaços.

As pesquisas pós-críticas, seguindo os caminhos já criados ou traçando novas rotas, variavam os focos de investigação. Inventaram o currículo como linguagem (Corazza, 2001), o currículo como fetiche e como representação (Silva 1999) e o currículo-mapa (Paraíso, 2003). Discutiram as relações entre o pensamento nietzschiano e as tendências contemporâneas, representadas pelo pósestruturalismo, para refletirem sobre uma teoria curricular. Analisaram a fusão entre currículos oficiais e alternativos (Corazza, 2000) e incentivaram práticas educacionais como, por exemplo, as etnomatemáticas (Bampi, 2000).

O lugar da linguagem na construção social é outro ponto a ser destacado para compreender a consequência dessa virada culturalista dentro da teorização curricular. Para os téoricos dessa abordagem, como William Pinar (1976) e Henry Giroux (1983), a linguagem constrói o mundo ao invés de simplesmente representá-lo, ou melhor, a linguagem cria aquilo de que fala. Nesse sentido, o currículo é, em si, visto como uma prática discursiva na interseção entre diversos discursos culturais e sociais que são criados e recriados. Essa recriação gira em torno das relações de poder e, como é somente no encontro em que ela se torna possível, nem tudo pode ser enunciado.

Segundo os autores da corrente pós-crítica, o currículo visto como narrativa étnica, conseguiu reafirmar uma ampliação e, até mesmo, uma superação do pensamento curricular da teoria crítica que apontava a dinâmica de classe como única no processo de reprodução das desigualdades sociais. Questões como etnia, gênero e raça configuram um novo repertório educacional significativo. Insistindo nesse processo, afirmam que tais questões apenas recentemente estão sendo problematizadas dentro do currículo, a partir de análises pósestruturalistas e dos estudos multiculturais.

\footnotetext{
${ }^{3}$ Traduziu inúmeras obras do francês Henry Giroux.
} 
Basicamente, esse campo de investigação, cujo impulso inicial foi examinar a cultura através de grandes obras literárias, vistas como burguesas e elitistas, criticou alguns conceitos e discursos da modernidade como, por exemplo, o progresso, a razão e a própria ciência. Tudo isso refletiu de forma significativa na elaboração curricular, que se caracterizava pela desconfiança no pensamento moderno, isto é: o saber totalizante, o progresso cumulativo, a razão iluminista, as verdades inquestionáveis e o sujeito livre e racional. Daí que apresenta-se, por exemplo, a radicalização póscrítica do conceito de diferença, que substituiu o de desigualdade, típico da modernidade. É nesse caminho também que a teoria questionou o significado do currículo como um instrumento político que se vincula à ideologia, à estrutura social e ao poder. No entanto, e como reconhece Apple, "a educação é intrinsecamente política mesmo nos seus caminhos mais práticos e tortuosos." (1999, p. 13, grifo nosso).

Num percurso histórico tão curto de construção do campo curricular, constata-se que com a incorporação do pensamento pós-crítico, a noção de um currículo como conhecimento selecionado para ser ensinado a todos, em prol de um projeto de formação de sujeitos e de transformação social, foi totalmente desestabilizada. Uma vez que se questiona o sujeito centrado e com identidades fixas, os projetos curriculares que buscam uma formação consciente e emancipada do estudante são abalados. Ao desconsiderar a importância da existência de projetos em relação ao futuro, os programas de formação para uma determinada sociedade sempre serão contestados. Tal afirmação resulta na reflexão sobre como se constrói politicamente o que se entende por social. Essa e muitas outras indagações, a respeito do processo de construção curricular, serão apresentadas e problematizadas no decorrer dos próximos capítulos.

\section{OS GUIAS CURRICULARES E A PROPOSTA DA CENP}

No início da década de 1970, durante o regime militar, verificava-se no Brasil uma crescente preocupação com a elaboração de currículos oficiais para a educação básica. O crescimento populacional brasileiro, o aumento da demanda por vagas na escola pública, a ampliação da rede de ensino, enfim, a rápida expansão do sistema educacional sem o oferecimento de uma formação adequada para os professores, "forçou" a elaboração de um currículo mínimo para orientar a ação docente no ensino básico.

Nesse processo de repensar as políticas educacionais do país, houve a implantação da Lei 5.692/71 que, alicerçada pelos Guias Curriculares (São Paulo, Estado, 1975), contribuiu para causar graves danos à formação de toda uma geração de estudantes. De um lado, a lei instituía as licenciaturas curtas para formar professores de maneira aligeirada, e realizava mudanças na grade curricular como a criação das disciplinas de Estudos Sociais, Educação Moral e Cívica e Organização Social e Política Brasileira (OSPB). Do outro lado, os Guias Curriculares pretendiam ajustar o estudante a um meio onde ele deveria viver e conviver de acordo com algumas "normas", em outras palavras, era preciso não criar condições de contestação do cenário político vigente (Kimura, 2009).

Os Guias Curriculares, mais conhecido como Verdão, elaborados pela Secretaria de Educação do Estado de São Paulo, tornaram-se uma espécie de "bíblia" do trabalho pedagógico. A 
tecnoburocracia do sistema educacional exigia a obediência dos conteúdos desse documento na formulação do plano de ensino de cada professor. Os conteúdos eram desenvolvidos de maneira isolada e descritiva, não havia nenhuma articulação entre eles, ou seja, não faziam parte de um processo integrado.

Para que se tenha uma dimensão da repressão que os Guias impunham a qualquer atividade escolar que destoasse das suas instruções, nada melhor do que um relato de quem viveu sob esse regime castratório:

em uma escola pública estadual da periferia do município de São Paulo onde lecionei, convidamos um grupo teatral que abordava a História do Brasil em que os personagens históricos eram encenados sob a forma de caricaturas ridicularizantes. No dia seguinte, fomos intimados a comparecer na sede do II Exército para prestar esclarecimentos. Foram muitas as ocasiões, também, em que, no retorno da escola para casa à noite, deparava-me com uma blitz para os soldados vistoriarem os bagageiros dos carros. (Kimura, 2009, p. 21).

Ainda nesse período nada democrático, para agravar, ainda mais, a situação educacional do país, o mercado editorial começou a inundar as escolas com livros didáticos que reproduziam os conteúdos abordados pelos Guias Curriculares. Do mesmo modo que os Guias serviram de apoio à implantação da Lei 5.692/71, os livros didáticos serviram para estabelecer a hegemonia dos Guias, traduzindo seus temas e instruções e trazendo em sua capa um pequeno aviso: de acordo com os Guias Curriculares.

Pode-se notar, claramente, que foram grandes as repercussões da ditadura militar na formação dos indivíduos. No entanto, a década de 1980, marcada pela redemocratização do país, transformava-se no momento ideal para se pensar em uma mudança curricular. Nesse contexto, no ano de 1984, em São Paulo, buscando sair da camisa de força dos Guias Curriculares, a Coordenadoria de Estudos e Normas Pedagógicas (CENP), órgão da Secretaria do Estado da Educação, constituiu uma equipe de autores, composta por pesquisadores de universidades públicas e professores da educação básica, para a elaboração de uma proposta curricular estadual.

Pela primeira vez, uma proposta de ensino buscava constituir canais de interlocução com os professores das escolas públicas, apresentava uma metodologia de trabalho que raramente se fazia presente em um discurso oficial e expunha, de forma discursiva, os conteúdos dos temas a serem trabalhados. A Proposta da CENP, como ficou conhecida, tornou-se um documento referência, presente nas discussões de várias universidades espalhadas pelo país, influenciando a construção de propostas curriculares em outros estados da federação.

Foram convidados inúmeros professores da Universidade de São Paulo (USP) para elaborarem e efetuarem uma revisão metodológica dos conteúdos disciplinares sob a luz dos pressupostos da teoria crítica. Com a abordagem crítica atuando na mudança curricular, apoiada pelo método dialético, o objetivo do ensino tornava-se outro. A intenção não era mais aquela dos Guias Curriculares, de "ajustar" o estudante para permanecer calado frente à realidade, mas sim a de procurar desenvolver nesse a capacidade de observar, analisar, interpretar e pensar criticamente a realidade. A realidade era concebida como uma totalidade que deveria englobar a sociedade e a 
natureza. À disciplina de Geografia, por exemplo, caberia a compreensão do espaço produzido pela sociedade, suas desigualdades e contradições, as relações de produção e a apropriação da natureza pela sociedade (São Paulo, Estado, 1984).

Ao trazer à tona a análise mais polêmica da época, a Proposta da CENP questionava a presença dos elementos vigentes do ensino tradicional. Segundo os autores da proposta, esse tipo de ensino ocultava as questões sociais e estava preocupado com a descrição dos conteúdos de maneira fragmentada, sem conseguir explicar a organização e a produção do espaço. Limitava-se, portanto, a um ensino comprometido "com os interesses das classes dominantes" e que servia "como instrumento ideológico de dominação e poder." (São Paulo, Estado, 1984, p.16).

A proposta da CENP teve a intenção de promover uma verdadeira ruptura no que chamava de ensino tradicional. Objetivava-se com essa proposta "transformar o aluno de receptáculo de informações em um ser crítico, capaz, desde o início da aprendizagem, de criar/construir o saber." (São Paulo, Estado, 1984, p. 17). Para isso, apontava-se alguns caminhos diferentes de uma orientação baseada apenas na transmissão do professor, descolada das necessidades sociais e da realidade do país. Nesse processo, o professor, que antes era visto como um mero transmissor de conhecimento, foi colocado como um produtor do saber em parceria com o estudante. Talvez tenha sido esse o motivo pelo qual a proposta obteve uma receptividade bastante variada entre os professores. Não só entre os professores da educação básica, mas também entre aqueles que pertenciam ao meio acadêmico, a proposta foi alvo de grandes polêmicas, principalmente quando colocava-se em questão o método utilizado.

A repercussão da Proposta da CENP nos diversos setores da sociedade, principalmente os capítulos destinados à Geografia e História, chamou a atenção da imprensa que também aproveitou para fazer suas acusações. Nos jornais, a proposta de Geografia, a disciplina mais acometida, foi acusada de valorizar "apenas o socialismo", conforme o título do artigo publicado no Estado de São Paulo de 13 de setembro de 1987 (Figura 01), de privilegiar a visão crítica (Figura 02) e de incitar à luta de classes (Figura 03). Em outras palavras, a proposta constituía-se em uma "ameaça comunista", segundo os veículos de comunicação.

Embora não tenha sido implementada, como aconteceu com os Guias Curriculares, a Proposta da CENP conseguiu incomodar muita gente, principalmente no âmbito educativo. Destarte, no início da década de 1990, a Secretaria Estadual de Educação de São Paulo reformulouse internamente e a proposta curricular saiu do foco da discussão, sendo tratada de maneira secundária. Nesse ínterim, os currículos escolares estaduais foram analisados por meio de um convênio entre a Fundação Carlos Chagas (FCC), o Ministério da Educação (MEC) e a Organização das Nações Unidas para a Educação, a Ciência e a Cultura (UNESCO). Esse convênio reuniu alguns professores universitários renomados e produziu um documento sob o nome de "As propostas curriculares oficiais", com a finalidade de subsidiar a elaboração de uma nova proposta: os Parâmetros Curriculares Nacionais (PCNs). 


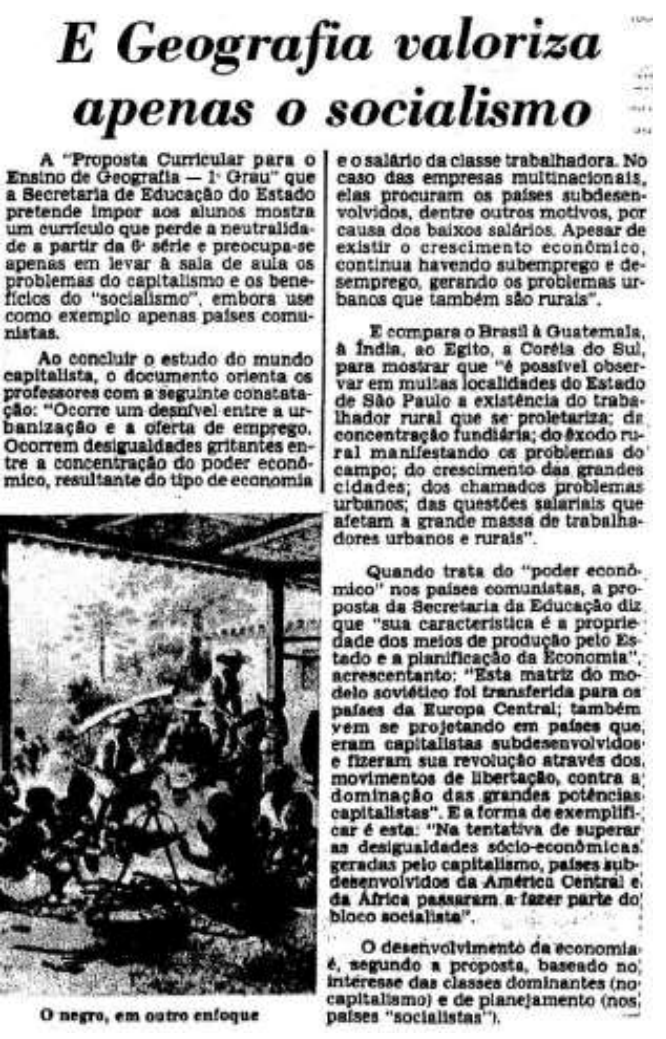

Figura 01: Artigo do jornal Estado de São Paulo.

Fonte: Estado de São Paulo, 13 set. 1987. Educação, p. 28.

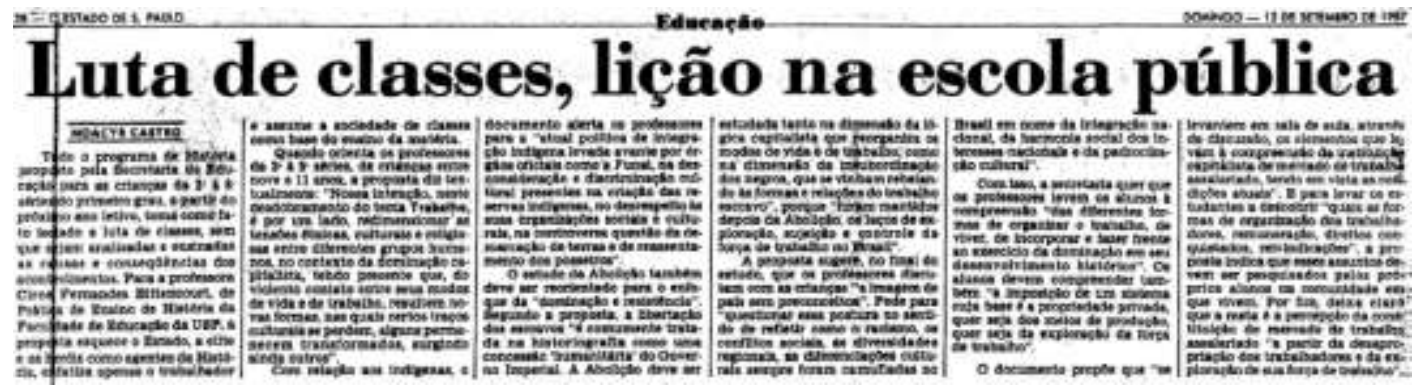

Figura 02: Artigo do jornal Estado de São Paulo.

Fonte: Estado de São Paulo, 13 set. 1987. Educação, p. 28.

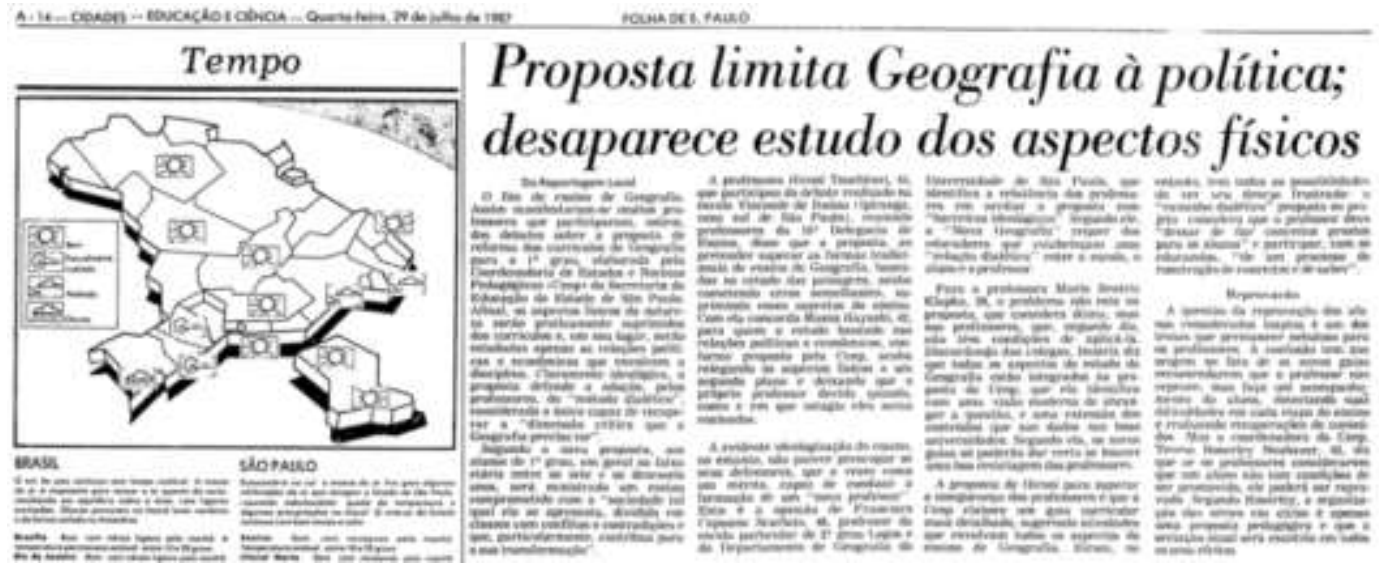

Figura 03: Artigo do jornal Folha de São Paulo.

Fonte: Folha de S. Paulo, 29 jul. 1987. Educação e Ciência, Caderno A-14, p. 32. 
Segundo os autores desse documento, os currículos escolares elaborados pelas Secretarias de Educação de diversos estados continham inúmeros problemas e, por esse motivo, cada disciplina no interior dos currículos precisaria ser revista. No caso da proposta curricular do estado de São Paulo, a Proposta da CENP, a crítica foi mais acentuada: "o objetivo de doutrinação político-ideológica é o eixo estruturador da proposta, sendo responsável tanto pela sua bem assentada coerência interna, quanto pelos problemas que podem ser diagnosticados em seu corpo. " (Moraes, 1995, p. 107, grifo do autor).

Um dos analistas, o professor Antônio Carlos Robert de Moraes, argumentou que a proposta visava consolidar no aluno uma "dada visão de mundo" encarada como a verdadeira, constituindose, assim, em uma doutrinação científica que negava o objetivo enunciado pelo próprio documento, o de valorizar a potencialidade crítica do aluno. Segundo ele, havia um "certo" e um "errado" préestabelecidos na proposta curricular, "num processo educativo que busca fomentar a formação valorativa dos discentes e docentes e sua capacidade de interpretar o mundo." (Moraes, 1995, p. 108). No entanto, uma leitura atenta da Proposta da CENP já serve para contestar esses apontamentos em questão:

O professor deve se envolver não só com os alunos, mas sobretudo com os conteúdos a serem ensinados. Ou seja, o professor deve deixar de dar conceitos prontos para os alunos, e sim, juntos, professores e alunos participarem de um processo de construção de conceitos e de construção do saber. (São Paulo, Estado, 1984, p. 17).

Pode-se notar que, apesar da construção curricular da CENP ter se aproximado de um modelo mais participativo, não logrou êxito na tentativa de inserir o professor como protagonista das mudanças escolares. Os contatos da CENP com os professores da rede pública ficaram muito vinculados a uma ideia de capacitação profissional. Cabia a esse órgão, principalmente, a tarefa de supervisionar e desenvolver materiais para o trabalho docente, o que ocasionou numa relação muito verticalizada com os professores. Essa distância entre planejamento e execução dificultou a construção de um projeto participativo. De fato, existia um louvável impulso coletivo que deu ensejo ao nascimento da proposta, mas logo depois esse impulso foi substituído pela simples vontade de um punhado de especialistas.

No início dos anos 1990, a Proposta da CENP saia de cena e dava espaço para outro documento: os Parâmetros Curriculares Nacionais (PCNs). Infelizmente, mesmo com essa mudança, os professores ficavam, mais uma vez, ausentes do processo criativo. Desapareceu até mesmo, como se descreverá adiante, essa tentativa de comunicação com os professores, originada no desenvolvimento da Proposta da CENP. 


\section{OS PCNS, AS DIRETRIZES CURRICULARES DO PARANÁ E O CURRÍCULO DE SÃO PAULO}

A crítica da Proposta da CENP caminhava para a defesa de um embasamento teóricometodológico que viria sustentar os PCNs, a fenomenologia. Essa orientação metodológica, ao tratar a questão do ensino dentro das bases fenomenológicas, procurou realçar os temas da consciência e da representação do espaço como uma espécie de experiência vivida. Essa tendência foi um reflexo da influência internacional que todo o país vinha sofrendo com a ampliação das políticas neoliberais promovidas após o Consenso de Washington em 1989. A meta nacional, portanto, tornava-se a de vincular a educação aos planejamentos econômicos globais como forma de contribuição para o desenvolvimento econômico do Estado.

Um ano após o Consenso de Washington, o Brasil participava da Conferência Mundial de Educação para Todos. Tal conferência, realizada na Tailândia e convocada pela UNESCO, pelo Fundo das Nações Unidas para a Infância (UNICEF), pelo Programa das Nações Unidas para o Desenvolvimento (PNUD) e pelo Banco Mundial, fez com que o país assumisse alguns compromissos que resultaram na elaboração do Plano Decenal de Educação para Todos (1993-2003). Este plano foi concebido como um conjunto de diretrizes políticas voltado para o aprimoramento e a avaliação dos sistemas escolares. Sua forte influência fez com que o Estado elaborasse parâmetros curriculares, alinhados aos ideais neoliberais, para orientar as práticas educativas da educação básica.

A Lei de Diretrizes e Bases da Educação Nacional (Lei Federal n. 9.394), aprovada em 20 de dezembro de 1996, reforçou, ainda mais, a necessidade de se propiciar a todos uma formação básica comum. Desse modo nasciam os PCNs, dentro de um contexto político internacional de iniciativas neoliberais, financiadas pelo Banco Mundial, que pretendiam adequar a educação às necessidades de qualificação de mão de obra demandada pelo mercado de trabalho, ou seja, a ideia era formar um sujeito polifuncional, empreendedor, criativo e competitivo, que estivesse apto para as mudanças constantes.

Os Parâmetros Curriculares Nacionais foram publicados em 1997. O documento foi composto por 10 volumes, dentre os quais, um volume possuía o material introdutório, seis volumes foram destinados aos componentes curriculares nas áreas de: Língua Portuguesa, Matemática, História, Geografia, Artes e Educação Física; e os outros três volumes contemplaram os temas transversais.

Assim como na criação das outras propostas curriculares, na discussão para a elaboração dos parâmetros, participaram docentes de universidades públicas e particulares, especialistas e técnicos de secretarias estaduais e municipais de educação. Os únicos que não apareceram durante esse processo, novamente, foram os professores da educação básica.

Os coordenadores e diretores estavam às voltas com a Proposta da CENP quando veio uma outra, única para todo o País: os PCN. O susto dos professores foi maior ainda porque, se na gestação das propostas anteriores, eles tiveram alguma participação por meio de representação, os PCN, diferentemente, chegaram sem aviso, de forma impositiva. Os professores, principais sujeitos do 
ensino formal, ficaram à margem de sua produção, tendo acesso ao documento somente depois de sua publicação. (Pontuschka et al., 2007, p. 80).

A determinação de um currículo centralizador e hegemônico desrespeitava o professor na medida em que desconsiderava suas experiências e os seus saberes acumulados na vivência cotidiana. Os PCNs foram organizados para serem aplicados em todas as escolas do Brasil, passando por cima de todas as contradições existentes nos diferentes grupos sociais. Dessa forma, estabeleceu-se a definição dos conteúdos "de cima para baixo" com o propósito de obter, através de uma homogeneidade, a "garantia de uma qualidade". Nessa trajetória, o professor perdeu o pouco que lhe restava da autonomia conquistada com as propostas geradas no processo de redemocratização. Ficou, ainda mais, limitado para pensar alternativas, escolher e participar da produção de conhecimento.

Utilizando argumentos que defendiam uma "escola autônoma" e um "ensino para o futuro", os PCNs buscavam constituir-se como um referencial de "qualidade para a educação" (Brasil, 1998). Entretanto, em uma rápida análise, percebe-se facilmente as contradições desse documento: ao mesmo tempo em que expõe uma ideia de autonomia do projeto pedagógico da escola, propõe avaliações externas para os três níveis da educação básica, o que rompe com a autonomia didáticocientifica dessas instituições.

Outra questão importante é que, embora tenha havido a preocupação, segundo os autores, de realizar uma proposta plural, ela acabou se tornando eclética. Há momentos em que se percebe um direcionamento fenomenológico e, em outros, há um claro direcionamento historicista. Essa pluralidade no embasamento teórico-metodológico resultou em uma abordagem superficial dos conteúdos, que propunha ao estudante uma simples constatação de sua realidade ao invés de uma profunda compreensão da mesma.

Os conteúdos separados em eixos, temas e itens, conseguiam demonstrar as diferenças de temporalidades no espaço, mas não havia uma intenção dos autores em conduzir o estudante a um aprofundamento sobre os mecanismos sociais e econômicos que determinavam essas diferenças. Nota-se aqui um predomínio de uma visão sociocultural na compreensão da sociedade, sendo minimizada a perspectiva socioeconômica. No entanto, uma inovação trazida pelos PCNs foram os temas transversais: ética, saúde, meio ambiente, orientação sexual, pluralidade cultural, trabalho e consumo. Buscou-se, com esses temas, uma maior interação com os demais conteúdos na tentativa de alcançar uma formação integral do estudante. $O$ único problema foi a forma autoritária com que foram impostos nas escolas distribuídas por todo o território brasileiro.

Foi a partir desse contexto que o estado do Paraná, incomodado com as concepções teóricas apresentadas pelos PCNs, iniciava em 2003 a elaboração das Diretrizes Curriculares da Educação Básica, concretizada somente no ano de 2008. O documento dividiu-se em três partes: na primeira parte demonstrou-se algumas formas históricas de organização curricular e expôs a concepção de currículo dos autores; na segunda parte apresentou as disciplinas da educação básica e seus fundamentos teórico-metodológicos, conteúdos e práticas pedagógicas e, por fim, na terceira parte trouxe uma tabela de conteúdos básicos de cada disciplina de acordo com o ano escolar. 
As Diretrizes Curriculares foram constituídas sob a perspectiva da crítica social da realidade. O documento surgiu com a finalidade de orientar o trabalho pedagógico dos professores da rede pública, buscando, principalmente, superar as vulnerabilidades teóricas dos Parâmetros Curriculares Nacionais e não apenas reproduzi-las como ocorreram em outros estados. Desde o início, destacou-se o papel protagonista que os professores desempenharam na elaboração das Diretrizes. Com a supervisão da Secretaria de Estado da Educação (SEED), foram organizados encontros, cursos, reuniões e palestras com professores da educação básica de todas as disciplinas, tendo como objetivo compreender quais eram os métodos, concepções e conteúdos vigentes nas escolas do Paraná. Esse processo permitiu um direcionamento, por meio do grupo de coordena ção da SEED, que indicou leituras e atividades no intuito de auxiliar os professores na construção da perspectiva teórica que o documento seguiria.

Embasada pela pedagogia histórico-crítica, as Diretrizes Curriculares do Paraná manifestava em seus fundamentos teórico-metodológicos inúmeros contrapontos aos PCNs. Havia um certo consenso, por parte da SEED, de que os Parâmetros atendiam aos interesses neoliberais e possuíam um ecletismo teórico que deveria ser superado. Concebidas desse modo, as Diretrizes exigiram dos professores um cuidado maior no que diz respeito à clareza dos princípios metodológicos que utilizariam no processo ensino-aprendizagem.

Por sua vez, os PCNs não apresentaram uma alternativa teórica consistente, ao contrário, assumiram um ecletismo ancorado numa concepção filosófica, no mínimo, pouco clara e confusa. [...] Assim, a falta de crítica, o ecletismo teórico e a ênfase na abordagem dos temas transversais diminuíram a importância, nos PCNs, das especificidades das disciplinas como campos do conhecimento. (Paraná, 2008, p. 48-49).

Como pode-se notar, a situação vivenciada no Paraná foi atípica em relação às outras propostas curriculares presentes no Brasil. Foi atípica não só porque a construção das Diretrizes exigiu a participação direta dos professores, mas também porque proporcionou um retorno à reflexão e pesquisa das linhas pedagógicas que estavam presentes na política educacional estadual e nacional. Contudo, esse caminho metodológico produziu e tem produzido até hoje algumas confusões conceituais, instigando inúmeros debates e contradições entre professores e entre esses e a Secretaria de Educação do Estado do Paraná.

Um exemplo do que se afirmou acima pode ser encontrado no trabalho de Baczinski, Piton e Turmena (2008). Nesse trabalho foram realizadas entrevistas com professores das escolas estaduais do município de Palmas, no estado do Paraná, e foi constatado que os mesmos conheciam a base epistemológica da proposta curricular, mas a prática pedagógica não era efetivamente implementada em sala de aula.

Em síntese, as respostas dadas pelos educadores giram em torno das seguintes afirmações: "É colocada em prática por parte de poucos"; "Falta comprometimento por parte da maioria dos docentes"; "A proposta não está implantada em sua totalidade, existe ainda muitas resistências por parte dos professores, principalmente porque muitos não estão preparados para a função de professor"; "Ainda não é praticada em sala de aula, pois muitos não têm o conhecimento necessário 
da pedagogia vigente e também falta interesse por parte dos professores de ver e realizar mudanças"; "A proposta é pouco trabalhada, para não ser pessimista e dizer que não é trabalhada." "Parece que essa proposta foi implantada pela SEED". (Baczinski et al., 2008, p. 147-148, grifo do autor).

Através das falas desses professores entrevistados, nota-se a existência de contradições a respeito da suposta oficialização de tal concepção teórica. Ao serem questionados sobre a eficácia dos pressupostos teóricos da pedagogia histórico-crítica, é possível identificar que os docentes enxergam o insucesso da sua implantação como resultado da própria atuação, que julgam ser insuficiente. Esse tipo de argumentação vem ao encontro da ideologia capitalista que por trás de ações mascaradas de coletividade responsabiliza e culpa o indivíduo pelo sucesso ou fracasso do resultado dessas ações. Isso demonstra a "incorporação do discurso capitalista burguês em detrimento dos pressupostos socialistas, de totalidade e coletividade defendidos pela Pedagogia Histórico-Crítica." (Baczinski et al., 2008, p. 148)

Sem dúvida, a elaboração das Diretrizes Curriculares representou um avanço nas políticas públicas enquanto processo democrático, porém, uma vez que se nega a concretização em sala de aula do que foi discutido durante cinco anos, nega-se também a construção coletiva tão exaltada durante todo processo. Dessa forma, percebe-se que a apropriação da pedagogia histórico-crítica, como embasamento teórico para as políticas educacionais, aconteceu por interesse do Estado em obter a hegemonia, não representando, porém, uma escolha da classe trabalhadora frente a suas necessidades e interesses reais.

De maneira bem diferente do que aconteceu no estado do Paraná, mas considerando também as dificuldades de operacionalização dos PCNs no cotidiano escolar, a Secretaria Estadual de Educação do Estado de São Paulo apresentou uma proposta curricular que se transformou em currículo oficial no ano de 2011. O documento surgiu com o objetivo declarado de organizar "de uma forma melhor" o sistema educacional de São Paulo. Para atender a esse objetivo, dividiu-se o documento em três partes: a primeira divisão carregou a proposta geral do trabalho, que trouxe as justificativas, os objetivos e as visões pretendidas; a segunda integrou um documento de orientações para a gestão do currículo na escola e a terceira divisão, agregou os cadernos específicos para os professores, separados em bimestres e em disciplinas, onde foram apresentados os conteúdos e as diretrizes para o trabalho do professor.

Pode-se notar que, mais uma vez, apresenta-se um currículo que prioriza o máximo controle das atividades desenvolvidas na escola e diminui a autonomia do professor. O Currículo de São Paulo, estabelecido sem uma prévia discussão com os professores, não concebeu a educação como um processo dialógico. É uma cartilha, uma nova instrução programada, que remete aos Guias Curriculares da ditadura militar. Esse material foi concebido por um grupo de especialistas que, em sua maioria, lecionam no ensino superior e/ou são autores de livros didáticos, ou seja, estão fora do terreno da educação básica, o que pode dificultar a realização de uma proposta que pretende se concretizar em sala de aula.

Desse modo, o atual Currículo do Estado de São Paulo sepultou, de uma vez por todas, aquele ímpeto, nascido no processo de redemocratização do país, de estabelecer uma discussão 
participativa com os professores. Configurando-se como uma proposta organizada de forma conservadora, tanto em relação ao seu processo como em relação ao seu conteúdo, dissociada das reivindicações e das vivências daqueles que estão mais próximos da escola real, o currículo criou uma visão idealista do professor, da escola e do estudante que não condiz com a realidade educacional brasileira.

Após seis anos de atividade do Currículo do Estado de São Paulo, dez anos dos PCNs e nove anos das Diretrizes do Paraná, como será que os professores se sentem em relação a esses? Será que esses documentos pautam as suas práticas pedagógicas? A nossa investigação não procurou registrar os depoimentos dos professores da educação básica acerca dessas questões. No entanto, são perguntas válidas para um debate que se faz necessário em torno de ações que possam oferecer ao professor a chance de atuar não somente na execução, mas também no planejamento das propostas curriculares, pois, como se sabe, um currículo imposto possui inúmeras fragilidades e limites que impedem a modificação das práticas educacionais.

\section{CONCLUSÃO}

Percebe-se que a elaboração de propostas curriculares tem sido uma prática comum, ao longo da história da educação brasileira, exercida pelas diversas secretarias de ensino, situando a ação do Estado entre a intervenção na formação docente e o controle do conhecimento aplicado nas escolas. Apresentou-se neste artigo cinco documentos curriculares para a educação básica: os Guias Curriculares, a Proposta da CENP, os Parâmetros Curriculares Nacionais, as Diretrizes Curriculares do Paraná e o Currículo de São Paulo. Esses foram produzidos em diferentes momentos e sob diversas conjecturas políticas, sociais e didático-pedagógicas.

Nesse sentido, esses materiais apresentam-se como ferramenta de melhoria da educação básica e refletem, portanto, as particularidades e exigências do período em que foram confeccionados, tal como as concepções teórico-metodológicas presentes na época. Os Guias curriculares, por exemplo, representam um esforço de um Estado autoritário que procura utilizarse de mecanismos repressivos para vetar o caráter crítico do ensino. Já, durante o período de redemocratização, a Proposta da CENP tenta contrapor a centralização de poderes no Estado e ampliar as discussões sobre as teorias críticas que subsidiam o trabalho docente. Um pouco mais adiante, com a ampliação das políticas neoliberais, os PCNs expressam as bases teóricas da fenomenologia dentro do processo educativo. Posicionando-se contra essa perspectiva adotada pelos parâmetros, emergem também as Diretrizes Curriculares do Paraná, em 2008, sob a luz dos pressupostos da pedagogia histórico-crítica fundamentada no materialismo histórico dialético. $E$, por fim, para operacionalizar os PCNs no cotidiano escolar, produz-se em 2011, o Currículo de São Paulo, dando sequência a manutenção das exigências neoliberais.

Apesar das diferenças apresentadas, a análise da elaboração desses documentos curriculares evidencia uma característica comum a ambos, a privação de uma discussão participativa com os professores da educação básica, sobre aquilo que pode ou não ser incluído como prática pedagógica nas escolas brasileiras. Conclui-se que há uma divisão dentro desse processo, onde, de um lado, estão aqueles que planejam e, do outro, àqueles que executam as propostas curriculares. 
A primeira esfera é reservada para os agentes educacionais que não estão envolvidos diretamente com a educação básica, enquanto, a segunda esfera, ligada somente à execução, restringe-se aos principais agentes do processo educativo, os professores.

Essas propostas, parâmetros e diretrizes demonstram o empenho do Estado na organização, criação e distribuição de práticas para orientar os professores da educação básica. Tal esforço parece não ter acabado, pois se está diante da formulação de um novo documento, hoje em dia, a Base Nacional Curricular Comum (BNCC). Traduz-se novamente em uma iniciativa do Ministério da Educação para se estabelecer um currículo comum nacional. Parece que, apesar da pressão dos diferentes agentes educacionais, o processo de sua constituição vem sendo mais um episódio costumeiro da nossa política curricular autoritária.

Um novo projeto educacional só poderá ser construído através do olhar direcionado para a prática escolar cotidiana. Dessa forma, a política curricular tem sua importância, assim como outros inúmeros fatores, mas a participação dos professores nessa construção é algo insubstituível.

\section{REFERÊNCIAS}

Althusser, Louis. (1998). Aparelhos ideológicos de Estado. Rio de Janeiro: Graal.

Apple, Michael. (1979). Ideology and Curriculum. New York: Routledge \& Kegan Paul.

Apple, Michael. (1999). Políticas culturais e educação. Porto: Porto Editora.

Baczinski, Alexandra Vanessa de Moura; Piton, Ivânia Marini; Turmena, Leandro. (2008). Caminhos e descaminhos da prática docente: uma análise da pedagogia histórico-crítica e das Diretrizes Curriculares do Estado do Paraná. Revista HISTEDBR On-line, (31), 142-152. Recuperado de http://www.histedbr.fae.unicamp.br/revista/edicoes/31/art11 31.pdf

Bampi, Lisete Regina. (2000). Currículo como tecnologia de governo de cidadãos e cidadãs. Reunião Anual da ANPED (pp. 1-05) Caxambu, MG. Recuperado de www.anped.org.br

Bobbit, Franklin. (1918). The curriculum. Chicago: Houghton Mifflin Company.

Brasil. (1998). Ministério da Educação. Secretaria de Educação Fundamental. Parâmetros Curriculares Nacionais. Brasília: MEC.

Corazza, Sandra Mara. (2000). Currículos alternativos-oficiais: o(s) risco(s) do hibridismo. In: Reunião da ANPED (pp. 200-205). Caxambu, MG. Recuperado de www.anped.org.br

Corazza, Sandra Mara. (2001). O que quer um currículo? Pesquisas pós-críticas em educação. Petrópolis: Vozes.

Dewey, John. (1959). Dewey on education: selections. New York: Teachers College Press.

Freire, Paulo. (1981). Educação e mudança. Rio de Janeiro: Paz e Terra. 
Freire, Paulo. (1985). The politics of education, culture, power and liberation. Nova lorque: Bergin \& Garvey.

Giroux, Henry. (1983). Theory and resistance in education. Londres: Bergyn \& Garvey.

Kilpatrick, William. (1918). The project method: the use of the porposeful act in the educative process. New York: Teachers College Press.

Kimura, Shoko. (2009). Território de luzes e sombras: a proposta de ensino de geografia da CENP. Terra Livre, (32), 17-30. Recuperado de http://www.agb.org.br/files/TL N32.pdf.

Libâneo, José Carlos. (1985). Democratização da escola pública: a pedagogia crítico-social dos conteúdos. São Paulo: Cortez Editora.

Moraes, Antônio Carlos Robert de. (1995). Propostas curriculares de Geografia. Projeto MEC/UNESCO/FCC. As Propostas Curriculares Oficiais / Subsídios a elaboração dos Parâmetros Curriculares Nacionais. São Paulo: FCC.

Paraná. (2008). Secretaria de Estado da Educação do Paraná. Diretrizes Curriculares da Educação Básica. Paraná: SEED-PR.

Paraíso, Marlucy Alves. (2003). Currículo-mapa: linhas e traçados das pesquisas pós-críticas sobre currículo no Brasil. Reunião anual da ANPED. Poços de Caldas, MG. Recuperado de www.anped.org.br

Pinar, William. (1976). Toward a poor curriculum. Nova York: Educator's International Press.

Pontuschka, Nídia Nacib; Paganelli, Tomoko lyda; Cacete, Núria Hanglei. (2007). In: A disciplina escolar e os currículos de Geografia. Para ensinar e aprender Geografia (pp 57-86). São Paulo: Cortez Editora.

São Paulo - Estado. (1975). Secretaria da Educação. Guias curriculares propostos para as matérias do núcleo comum do ensino de 1ํ grau. Coordenação geral: Delma Carchedi. São Paulo: SE/CERHUPE.

São Paulo - Estado. (1984). Secretária da Educação.). Coordenadoria de Estudos e Normas Pedagógicas. Proposta curricular: ensino fundamental. São Paulo: SE/CENP.

São Paulo -Estado. (2011). Secretaria da Educação. Currículo do Estado de São Paulo. Coordenação Geral: Maria Inês Fini. São Paulo: SE.

Saviani, Dermeval. (1991). Pedagogia Histórico-Crítica. Campinas: Autores Associados.

Silva, Tomas Tadeu da. (1999). O Currículo como prática de significação. In: . O currículo como fetiche: a poética e a política do texto curricular (pp 07-30). Belo Horizonte: Autêntica.

Tyler, Ralph. (1975). Princípios básicos de currículo e ensino. Porto Alegre: Globo. 
Young, Michael. (1971). Knowledge and control: new directions for the Sociology of Education. Michigan: Macmillan. 